\title{
O PLANEJAMENTO TERRITORIAL NO PARANÁ BASEADO NA ATUAÇÃO DO MOVIMENTO ECONOMIA E HUMANISMO NO BRASIL
}

\author{
Lucas Ricardo Cestaro* \\ Fabíola Castelo de Souza Cordovil** \\ *Universidade Federal do Paraná, Departamento de Arquitetura e Urbanismo, Curitiba, PR, Brasil \\ ** Universidade Estadual de Maringá, Departamento de Arquitetura e Urbanismo, Programa de Pós-graduação \\ em Geografia, Maringá, PR, Brasil
}

\begin{abstract}
Resumo
Analisamos a atuação do Movimento Economia e Humanismo no Brasil com base nas ações da Sociedade para Análises Gráficas e Mecanográficas Aplicadas aos Complexos Sociais (SAGMACS), investigando as filiações teóricas e metodológicas em trabalhos elaborados pelo grupo para o estado do Paraná, entre 1955 e 1958 e em 1963. Esses trabalhos, realizados no campo disciplinar do planejamento urbano e regional, visavam à modernização do estado e de sua máquina administrativa e ao desenvolvimento econômico. Destacamos a relevância da SAGMACS no planejamento do território brasileiro considerando as publicações do Movimento Economia e Humanismo e de outros pensadores, cotejadas com a literatura que evidenciou as matrizes conceituais do grupo fundado na França, em 1941. Foi possivel verificar que as ações da equipe coordenada por Louis-Joseph Lebret contribuíram para a institucionalização do planejamento regional no Brasil, para a formação de instituições de urbanismo e órgãos de assistência técnica, além de resultarem na reorganização do território do Paraná, indicando o planejamento dos seus polos regionais.

Palavras-chave

Planejamento Urbano e Regional; Plano de Desenvolvimento; SAGMACS; Louis-Joseph Lebret.
\end{abstract}




\title{
TERRITORIAL PLANNING IN PARANÁ AS RESULT OF ACTING BY ECONOMY AND HUMANISM MOVEMENT IN BRAZIL
}

\author{
Lucas Ricardo Cestaro* \\ Fabíola Castelo de Souza Cordovil ${ }^{* *}$ \\ *Universidade Federal do Paraná, Departamento de Arquitetura e Urbanismo, Curitiba, PR, Brazil \\ ** Universidade Estadual de Maringá, Departamento de Arquitetura e Urbanismo, Programa de Pós-graduação \\ em Geografia, Maringá, PR, Brazil
}

\begin{abstract}
The acting of Economics and Humanism Movement in Brazil is analyzed based on the actions of the Society for Graphic and Mechanographic Analyses Applied to Social Complexes (SAGMACS), investigating the theoretical and methodological affiliatons in works prepared by the group for Paraná, between 1955 and 1958 and in 1963. These works, carried out in the urban discipline and regional planning, aimed at the modernization of the state, its administrative machine and economic development. We emphasize the relevance of SAGMACS in the planning of the Brazilian territory considering the publications of Economy and Humanism and other thinkers, connected with the literature that evidenced the conceptual matrices of the group founded in France in 1941. We verified that the actions of the team coordinated by Louis-Joseph Lebret contributed to the institutionalization of regional planning in Brazil, for the formation of urbanism institutions and technical assistance agencies, as well as resulted in the reorganization of the territory of Paraná, indicating the planning of its regional centers.

Keywords

Regional Planning; Development Planning; SAGMACS; Louis-Joseph Lebret.
\end{abstract}




\title{
O PLANEJAMENTO TERRITORIAL NO PARANÁ BASEADO NA ATUAÇÃO DO MOVIMENTO ECONOMIA E HUMANISMO NO BRASIL
}

\author{
Lucas Ricardo Cestaro \\ Fabíola Castelo de Souza Cordovil
}

Introdução

O período pós-Segunda Guerra Mundial inaugurou no mundo uma nova estrutura geopolítica, na qual países europeus sofreram com o declínio de sua hegemonia política, cultural e econômica em relação aos demais países e assistiram à ascensão da hegemonia estadunidense, polarizada com a União das Repúblicas Socialistas Soviéticas (URSS). Essa polarização devia-se ao alinhamento dos Estados Unidos à economia capitalista e da URSS ao socialismo; denominada Guerra Fria, perdurou até a década de 1980.

A partir de 1945, os países da Europa iniciaram um processo de reconstrução de suas cidades e de seu parque industrial, que tinham sido arrasados pelos bombardeios sofridos durante o grande conflito mundial. Com a reconstrução dessas cidades e a criação do Ministério de Reconstrução e Urbanismo, houve espaço para que algumas ideias relativas à questão habitacional, à organização econômica e ao urbanismo fossem discutidas pelos europeus.

Já os países localizados na América Latina e na África também sofreram mudanças políticas, sociais e econômicas, em decorrência dos anos de guerra, sem, no entanto, ter suas cidades destruídas. Na década de 1950, esses países de economia periférica, que passaram a ser designados como pertencentes ao Terceiro Mundo, viviam, segundo Sauvy (1952, p. 14), “em situação ainda precária, apesar de apresentarem amplas possibilidades de melhoria e desenvolvimento social”. Diferentemente dos países europeus, que buscavam meios para a reconstrução das cidades 
arrasadas pela guerra, os países do Terceiro Mundo discutiam outras questões e problemas; o Brasil, por exemplo, que tentava encontrar solução para os problemas do subdesenvolvimento, da industrialização, da modernização do Estado e da dependência econômica.

Assim, a década de 1950 abre espaço no Brasil para a crença no planejamento urbano e regional, devido à euforia econômica - causada pelo saldo excedente na balança comercial e pelo desenvolvimento da indústria nacional - e política - decorrente da reabertura democrática e do retorno das eleições diretas para a presidência da República. Ao mesmo tempo, percebiam-se, durante o governo Dutra, dificuldades da elite dirigente e dos empresários do país em organizar um projeto de desenvolvimento nacional, acentuadas pelo tensionamento da problemática regional entre Norte/Nordeste e Sul/Sudeste e o necessário equacionamento dos desequilíbrios regionais. A crença no planejamento não só fomentou o debate acerca do nacional-desenvolvimentismo, da intensificação do processo de industrialização e da urbanização, como também propiciou a criação de órgãos de assistência técnica e a ampliação da atuação de consultores estrangeiros voltados para a elaboração de planos urbanos regionais.

No contexto do pós-guerra, foram criados a Fundação Getulio Vargas (em 1944), o Instituto Brasileiro de Administração Pública (Ibam) (em 1952), ambos no Rio de Janeiro; a Sociedade para Análises Gráficas e Mecanográficas Aplicadas aos Complexos Sociais (SAGMACS), fundada em São Paulo (em 1947) pelo frei francês Louis-Joseph Lebret; o Centro de Estudos e Pesquisas Urbanísticas (Cepeu), dirigido por Luís Anhaia Melo, como órgão vinculado à Faculdade de Arquitetura e Urbanismo da Universidade de São Paulo (em 1955); e o Centro de Pesquisas em Planejamento Urbano e Regional (Cepur), criado pelo engenheiro Antônio Bezerra Baltar, dentro da Universidade do Recife (em 1955).

Nesse cenário, o objetivo deste texto é analisar os trabalhos realizados pela equipe de Lebret para o estado do Paraná publicados em 1958 e 1963, os quais tinham como propósito modernizar o Estado e a máquina administrativa e atuar sobre o desenvolvimento econômico. Para tanto, foram investigadas as ações da SAGMACS entre 1947 e 1964, período de atuação do órgão vinculado ao Movimento Economia e Humanismo (EH) francês, que coincide com o momento de ascensão da população urbana brasileira e com a tentativa de construir ações voltadas ao desenvolvimento econômico, relacionadas ao planejamento regional. Como percurso metodológico, partiu-se da pesquisa exploratória, com a análise dos documentos referentes aos trabalhos desenvolvidos pela SAGMACS para o Paraná e a revisão bibliográfica relativa à historiografia da formação e à institucionalização do quadro do urbanismo no Brasil, estudando especialmente o período do pós-guerra e 
os anos 1950, com ênfase nos ares da redemocratização do país. Assim, a atuação da SAGMACS foi situada no planejamento regional, revelando as filiações teóricas e metodológicas nos debates e na concepção de planos e de relatórios técnicos, valendo-se das publicações do EH.

A análise do primeiro trabalho ocorreu num âmbito panorâmico, uma vez que o estado do Paraná não era propriamente o objeto de intervenção, pois a SAGMACS fora contratada pela Comissão Interestadual da Bacia Paraná-Uruguai (CIBPU), órgão criado em 1951, como resultado de um convênio de cooperação entre sete estados, que gerou dois relatórios técnicos: SAGMACS. Problemas de desenvolvimento. Necessidades e possibilidades do estado de São Paulo (1955) e SAGMACS. Problemas de desenvolvimento. Necessidades e possibilidades dos estados do Rio Grande do Sul, Santa Catarina e Paraná (1958). Além de inserir o estado do Paraná no escopo dos trabalhos coordenados por Lebret no Brasil, a análise do relatório de 1958 permite compreender a inserção da SAGMACS junto ao meio da assistência técnica voltada ao planejamento regional, depois da primeira contratação de consultoria pela CIBPU.

O segundo trabalho em destaque consistiu na contratação, pelo governo paranaense, da equipe de Lebret no Brasil, no ano de 1963. O estudo, desenvolvido durante o mandato do governador Ney Braga (1961-1965), resultou numa proposta de diretrizes para o desenvolvimento do Paraná que tinha como finalidade, com base no desenvolvimento de comunidades territoriais, a reorganização física do Estado, respeitando-se as necessidades e as possibilidades de desenvolvimento de cada região e o fortalecimento da capital, Curitiba.

A delimitação em torno da atuação da SAGMACS no Paraná possibilita explorar documento pouco debatido entre os estudiosos da atuação de Lebret, em face dos trabalhos de Leme e Lamparelli (2001), Gardin (2009), Bosi (2012), Chiquito (2012a), Roldan (2012), Angelo (2013), Pontual (2016b) e Cestaro (2019). Assim, além de analisar as ações da SAGMACS na reorganização do território do Paraná, este artigo discute a institucionalização do quadro do urbanismo e do planejamento territorial no Brasil, situando o papel destacado do órgão, ao longo da década de 1950 e no início dos anos 1960.

\section{A fundação da SAGMACS como órgão de assistência técnica no Brasil e a vinculação com o Economia e Humanismo da França}

A reconstituição da formação histórica da SAGMACS remonta à fundação do EH, descrito no documento L'Origine d'Économie et Humanisme (1942). Formalmente inaugurado em 1941, com sede em Lyon na França, as matrizes conceituais e teóricas que nortearam o ideário lebretiano retroagem aos anos 1930, quando 
os religiosos Lebret e Suavet cogitaram a criação de um Centro de Estudos sobre o Marxismo, cujos objetivos seriam estudar a conjuntura política e econômica e pensar em formas de alcançar um desenvolvimento mais harmônico, no qual as necessidades do homem seriam vistas como centrais para nortear as ações da política econômica. Em meio à necessidade de reconstruir as cidades que haviam sido arrasadas durante a guerra, a partir de 1945 o debate na Europa sobre o provimento habitacional e o urbanismo ganhava peso. Nesse contexto, o EH, criado na França', em 1941, pelo dominicano Louis-Joseph Lebret, com o apoio do economista François Perroux, dos empresários René Moreaux e Alexandre Dubois, dos padres Marie-Reginald Loew e Henri Desroche e demais intelectuais católicos da França, vislumbrou possiblidades de inserção no contexto do pós-guerra.

Num primeiro momento, foi na França que Lebret e os adeptos do EH atuaram. Sob o argumento de construir essa terceira via econômica, Lebret encontrou junto ao Ministério da Reconstrução e Urbanismo, comandado por Raoul Dautry na França, o locus para se aproximar do aparelho de Estado e prestar apoio técnico em programas de reconstrução das cidades arrasadas pela guerra e de implantação de unidades habitacionais. A aproximação do grupo de Lebret com os democratas cristãos permitiu a expansão da ação do EH, que, em 1946, realizou estudos para quatro cidades francesas: Lyon, Marselha, Nantes e Saint-Etiénne. Esse fato obrigou o EH a criar laboratórios de pesquisas locais, constituídos sob a forma de associações. Foram criados o Centro Regional de Pesquisa e de Conjuntura (Crédoc), o Instituto Marselhês de Estatística e de Análise da Conjuntura (Imsac) e a Sociedade para Aplicação Gráfica e Mecanográfica para a Análise (Sagma). Além desses órgãos, em 1947, foi criada pelo grupo a Livraria Economia Humana, com destaque para as publicações da Revue Économie et Humanisme, desde 1942.

As publicações das revistas de Economia e Humanismo são objetos de estudo de Roldan (2012, p. 57), que aponta para a interface que ela apresenta com o ideário urbano. Em seu "primeiro número [trouxe] uma resenha de Loew sobre o 'Problème d'urbanisme', trabalho do urbanista francês Gaston Bardet”. Já o percurso de introdução das questões urbanas junto aos anseios do Movimento de Economia e Humanismo foi estudado por Pelletier (1996), Leme e Lamparelli (2001), Pontual (2011; 2016b), Angelo (2013) e Cestaro (2019), que se debruçaram sobre a atuação da

1. Segundo o Estatuto da Associação, o EH foi constituído para estudar as realidades humanas, econômicas e sociais, alcançando a elaboração de uma doutrina econômica e espiritualista e colocando a economia a serviço do homem, o Bem Comum. Visava, adicionalmente, à construção de uma terceira via, que não se dava pelo socialismo nem pelo capitalismo. 
SAGMACS $^{2}$. O Brasil, no período subsequente à Segunda Guerra Mundial, contava com excedente no saldo da balança comercial e passava pela modernização de seu parque industrial - o que refletiu no crescimento das cidades e no inchaço populacional em várias delas -, e acabou por entrar na rota de interesse do Movimento de Economia e Humanismo, marcando a expansão das atividades de Lebret e seu grupo junto ao Terceiro Mundo.

Lebret desembarcou no Brasil em abril de 1947, em viagem feita a convite do Prof. Cyro Berlinck, diretor da Escola Livre de Sociologia e Política (ELSP). Na ELSP, ele ministrou uma disciplina em que expôs a Economia Humana a estudantes da pós-graduação em Ciências Sociais. Foi nesse período que Lebret aproveitou para estreitar seus contatos no Brasil e para aperfeiçoar seu conhecimento sobre o Terceiro Mundo. Além dos padres dominicanos, ele se aproximou de importantes lideranças empresariais, como Olívio Gomes, e intelectuais, como os engenheiros Lucas Nogueira Garcez e Luiz Cintra do Prado, ambos da Escola Politécnica da USP, e do Prof. Luís Anhaia Melo, da Faculdade de Arquitetura e Urbanismo da mesma instituição. Ao final do curso na ELSP, Lebret fundou a SAGMACS, com o apoio de empresários paulistas e de intelectuais ligados à Escola Politécnica da USP, assim como da ELSP.

A fundação da SAGMACS ocorreu no ano em que Lebret visitou pela primeira vez Brasil, Chile, Argentina, Colômbia e Uruguai. Essa iniciativa aproximou o meio intelectual católico e o empresariado paulista do vínculo do ideário lebretiano entre o Brasil e a França, mais precisamente entre os membros ligados a Lebret em Lyon e a SAGMACS em São Paulo. Porém, uma declaração do padre francês sobre a cassação do registro do Partido Comunista do Brasil (PCB) tornou tensas suas relações com o governo Dutra e com a ala conservadora da Igreja católica, que prontamente articulou seu regresso ao seu país natal.

\section{A inserção da SAGMACS no planejamento territorial na década de 1950}

Os anos 1950 podem ser entendidos como a década da crença no planejamento urbano e regional no Brasil, definida por Feldman (2009, p. 1) como a “convicção de que o controle público é possível [...] e que tornar eficiente a organização territorial é um caminho para superar as desigualdades regionais”.

2. Além dos autores citados, cabe expor a contribuição de Lícia do Prado Valladares (2005) sobre a atuação de Lebret no Brasil e as tentativas de inserção junto ao meio intelectual, tanto no Brasil como na França, e o trabalho organizado por Jatobá e Araújo (2016), que analisa a realidade do Nordeste com base nas proposições de Lebret em 1954. VALLADARES, L. P. Louis-Joseph Lebret et les favelas de Rio de Janeiro (1957-1959): enquêter pour l'action. Genèses - Revue des Sciences Sociales et Histoire, Paris, n. 60, p. 31-56, set. 2005. JATOBÁ, F.; ARAÚJO, T. P. (org). Diálogos com Lebret: 60 anos depois. Recife: Cepe, 2016. 
Segundo Gardin (2009, p. 19), o Brasil apresentava naquele período graves problemas sociais e econômicos, que se desdobravam em problemas territoriais, "com regiões consideradas verdadeiros entraves ao desenvolvimento pretendido, como o Nordeste e a Amazônia". Diante desses problemas, a autora aponta que "havia um consenso em torno da necessidade de se desenvolver o país e também de que não havia recursos financeiros disponíveis internamente, o que implicava na busca de recursos no exterior".

Nesse contexto, a SAGMACS configurou-se como uma instituição de assistência técnica e contribuiu para o debate brasileiro acerca dos problemas do desenvolvimento, da dependência em relação aos países desenvolvidos e, principalmente, da modernização do Estado, por meio da participação em comissões governamentais e em contratos firmados para assessoria aos governos de estado, além do desenvolvimento de planos diretores para os municípios, durante a década de 1950 e o início da de 1960.

É importante situar que a SAGMACS apresentou percurso diferenciado em relação aos demais órgãos de assistência técnica dentro do debate sobre o planejamento urbano e regional no Brasil. Diferentemente das outras instituições fundadas, a exemplo do Cepeu e do Cepur, a SAGMACS, no início de suas atividades, não se vinculou diretamente ao campo do urbanismo, e isso se devia, conforme Cestaro (2019, p. 169), à própria condição político-econômica do país, “que, naquele momento, mostrava-se preocupado em garantir o desenvolvimento da indústria nacional, bem como manter-se menos dependente da importação de produtos industrializados". Assim, "as pesquisas da SAGMACS se situam no ponto de encontro político entre o Governo Federal e os poderes regionais e se inscrevem na lógica geral do desenvolvimentismo e de intervenção dos poderes públicos na gestão econômica do país” (LEME; LAMPARELLI, 2001, p. 680).

Diante dessa possibilidade de articulação com os poderes locais e regionais, e também com o Governo Federal, a SAGMACS inseriu-se no campo do urbanismo e do planejamento territorial depois do trabalho realizado junto à CIBPU ${ }^{3}$, criada por meio de um convênio de cooperação entre os estados que integravam a Bacia Paraná-Uruguai - São Paulo, Santa Catarina, Paraná, Mato Grosso, Rio Grande do Sul, Goiás e Minas Gerais ${ }^{4}$ Para Gardin (2009, p. 20), até aquele momento, a CIBPU e a Comissão do Vale do São Francisco "foram as únicas experiências de

3. A criação da CIBPU e suas contribuições para o planejamento territorial no Brasil foram estudadas por Gardin (2009) e Chiquito (2012a).

4. Para Chiquito (2012a, p. 151) e Pelletier (1996), a entrada da SAGMACS nos estudos regionais no Brasil se relaciona a três missões específicas solicitadas entre 1951 e 1952: i) a Missão Vargas pelo governo federal, ii) a Missão CIBPU e iii) a Missão Confidencial pelo governo do estado de São Paulo. 
planejamento regional no Brasil centradas no desenvolvimento de bacias hidrográficas", que, para essa autora, têm "base territorial advinda do modelo do planejamento norte-americano do vale do rio Tennessee (TVA)".

Cestaro (2019, p. 148) informa que, no campo do planejamento regional, houve "três fases distintas na atuação da SAGMACS no Brasil": a primeira delas foi a de constituição do órgão, nos anos iniciais do grupo, entre 1947 e 1952, em cuja linha de frente estiveram os engenheiros Lucas Nogueira Garcez e Luiz Cintra do Prado, quando a equipe era sediada no Jockey Club de São Paulo. A segunda fase inicia-se em 1952, “quando a instituição é contratada pelo governador Garcez para atuar junto ao CIBPU, realizando o estudo Problemas de desenvolvimento. Necessidades e possibilidades dos estados do Rio Grande do Sul, Santa Catarina e Paraná”. De acordo com o autor (idem, ibidem), o desenvolvimento urbano e regional passou a figurar, nessa fase, como tema de interesse e se concretizou em trabalhos junto a SAGMACS, tais como “[...] o 'Plano Diretor para a cidade de Ourinhos', realizado em 1954, e o estudo sobre os 'Polos para o Desenvolvimento do Estado de Pernambuco', que aproximou o padre Lebret do engenheiro pernambucano Antônio Bezerra Baltar, que atuou na coordenação do estudo da 'Estrutura Urbana da Aglomeração Paulistana', realizado para a Prefeitura de São Paulo em 1957” (CESTARO, 2019, p. 148-149).

A terceira e última fase, segundo Cestaro (2019), consiste no momento de distanciamento de alguns atores da equipe, que foram compor quadros técnicos do governo de Carvalho Pinto em São Paulo, e na alteração do Estatuto da SAGMACS, convertida em uma cooperativa de técnicos. Essa fase coincide também com um maior distanciamento de Lebret em relação à equipe e com sua morte, em 1966. Em 1963, a SAGMACS foi contratada pela Companhia de Desenvolvimento Paranaense (Codepar).

Nos limites deste texto, não é possível realizar um estudo comparativo aprofundado entre os dois trabalhos executados para o Paraná, com uma análise sobre a repercussão das teorias e conceitos utilizados pela SAGMACS, presentes em ambos, evidenciando suas modificações e permanências em dois contextos distintos de atuação. Todavia, no trabalho de 1958 a concepção dos polos de desenvolvimento pode ser verificada na delimitação das regiões e sub-regiões, conforme se vê na Figura 1, corroborando a análise de Chiquito (2012a), para quem, apesar de a concepção inicial da CIBPU basear-se nas ideias do Movimento Economia e Humanismo, ao longo dos anos 1950 a teoria dos polos de crescimento foi incorporada pelos técnicos até ocupar lugar de destaque na década seguinte. Evidenciando-se o contexto político e econômico, explicitam-se a seguir filiações teóricas e metodológicas utilizadas pela equipe, com base nos trabalhos desenvolvidos para o estado do Paraná. 
2.1 Aproximações da SAGMACS com o Paraná: a atuação da equipecom a criação da CIBPU

Com a eleição de Lucas Nogueira Garcez para o governo do estado de São Paulo, em 1950, o retorno de Lebret ao Brasil foi facilitado e abriu espaço para uma nova visita ao país. Garcez, aluno de Lebret na ELSP, foi um dos membros fundadores da SAGMACS.

Antes de ser empossado governador, Garcez enviou carta para Lebret na França, que respondeu com uma lista de sugestões para o plano de governo ${ }^{5}$. Tais sugestões foram transformadas pela equipe do governador no Plano Quadrienal, apresentado à Assembleia Legislativa. Garcez contratou a SAGMACS, sob coordenação de Lebret, em 1952, para o desenvolvimento de um plano de eletrificação para o estado. Sua preocupação com o setor elétrico se justificava em função do aumento da produção industrial e do reconhecimento dos riscos de que esse crescimento poderia não se sustentar em decorrência de problemas na infraestrutura.

Paralelamente a essa preocupação com os gargalos de infraestrutura e insuficiência do setor elétrico do estado, Garcez demonstrava desconforto com as ações do Governo Federal, sob a presidência de Vargas, que estava implementando medidas para fomentar o desenvolvimento dos estados do Nordeste brasileiro, objeto de estudo pela então recém-criada Comissão Econômica para a América Latina e o Caribe (Cepal), a partir de 1949.

No tocante a esse aspecto, o governador se apropriou da sugestão de Lebret, apontada no plano de governo, de extrapolar os limites físico-territoriais do estado e dar tratamento no âmbito do planejamento regional, olhando para além dos problemas de São Paulo, para aquilo que havia em comum em relação aos demais estados e regiões do país.

Garcez se empenhou junto aos demais governadores das regiões Sul e Sudeste para criar a CIBPU, oficializada pelo Governo Federal por meio da Lei ${ }^{\circ} 2.018$, de 23 de dezembro de 1952, que pretendia dar à comissão status de autarquia federal. Porém, conforme já apontado, não houve consenso entre Vargas e os governadores dos estados envolvidos. Apesar da oposição da União, "a criação da CIBPU contribuiu com instrumentos e arranjos institucionais até então não experimentados pela experiência brasileira de planejamento regional” (CHIQUITO, 2012b, p. 70). Assim, os governadores deram continuidade à criação do órgão, que passou a ser uma comissão interestadual, sob a tutela direta deles; foram elaboradas, inclusive, rubricas orçamentárias para sua manutenção e funcionamento.

5. As correspondências trocadas entre Lebret e Garcez estão depositadas na Pasta AN45 AS51, do Fundo Lebret, no Arquivo Nacional da França, em Fontainebleau. 
Com a CIBPU instituída, Garcez solicitou a Lebret e a SAGMACS um primeiro estudo sobre os problemas econômicos e sociais da região da Bacia Paraná-Uruguai, iniciado em 1952. Ao analisar o quadro do urbanismo e do planejamento regional no Brasil, fazendo uso de estudos técnicos produzidos tanto por órgãos públicos como por equipes de assistência técnica, Chiquito (2012a, p. 162) afirma que "o trabalho coordenado por Lebret pode ser considerado um marco para a instituição das ações de planejamento e desenvolvimento regional”. Segundo a autora, a importância do estudo se deve, "em primeiro lugar por ser inédito e, em segundo lugar, por ser abrangente, representando um esforço de compreensão e interpretação da realidade brasileira até então praticamente desconhecida pelo Estado e da possibilidade de comparação desta com outras regiões do mundo" (CHIQUITO, 2012a, p. 162).

O estudo contratado demandou dois anos de trabalho e exigiu da SAGMACS a formação de uma equipe. Até então, a Sociedade se projetava apenas mediante a atuação de alguns de seus membros, engajados em trabalhos técnicos e em comissões especiais instituídas por organismos públicos.

Em face da complexidade desse trabalho e da institucionalização da contratação junto ao aparelho de estado, a SAGMACS se viu em condições de encampar uma equipe grandiosa de pesquisadores, que contou com profissionais de diferentes áreas do conhecimento, como economistas, engenheiros, geógrafos e sociólogos. Foi nesse momento de realização do estudo SAGMACS. Problemas de desenvolvimento. Necessidades e possibilidades dos estados do Rio Grande do Sul, Santa Catarina e Paraná que os arquitetos, atuando ainda como estagiários e desenhistas, entraram em contato com a equipe de Lebret.

A metodologia para a realização da pesquisa seguiu o trabalho de levantamento empírico e de contato global utilizado pelo EH francês e impôs, inclusive ao padre Lebret, a necessidade de ir a campo, a fim de conhecer a realidade das cidades do interior paulista, numa atividade chamada por ele de "viagem de exploração”, que culminou com o relatório Conclusions provisoires du Voyage d'étude (LEBRET, 1952). Chiquito (2012a, p. 162) revela:

Em fevereiro de 1954, Lebret apresenta no Palácio dos Campos Elíseos os resultados preliminares do estudo "Necessidades e Possibilidades do Estado de São Paulo" com uma longa e minuciosa exposição a respeito dos métodos e princípios de pesquisa de Economia e Humanismo. O vice-presidente da CIBPU, Álvaro de Souza Lima, destaca "a importância do trabalho apresentado pela instituição, a objetividade das conclusões alcançadas, o cabedal precioso de dados e informações coligidas e, principalmente, os fecundos métodos de análise desenvolvidos por Economia e Humanismo” ressaltando 
ainda que tais métodos foram "pela primeira vez empregados no extenso e complexo campo dos problemas econômicos de uma área superior à de vários países da Europa”.

Durante sua visita às cidades do interior paulista, realizada em junho de 1952, e posteriormente a cidades do Rio Grande do Sul, de Santa Catarina, do Paraná, de Minas Gerais, do Mato Grosso e do Rio de Janeiro, Lebret foi capaz de perceber as disparidades regionais dentro de um mesmo estado (São Paulo) e também nas diferentes regiões do país.

Como o trabalho SAGMACS. Problemas de desenvolvimento. Necessidades e possibilidades dos estados do Rio Grande do Sul, Santa Catarina e Paraná havia sido contratado por intermédio da CIBPU, que extrapolava os limites físico-territoriais do estado, a SAGMACS conseguiu, na sequência da realização desse trabalho, ser contratada para desenvolver estudos semelhantes nos estados da região $\mathrm{Sul}^{6}$, executados entre os anos de 1955 e 1957, com o emprego da metodologia utilizada no estudo para São Paulo. A publicação ocorreu em 1958, sob patrocínio da CIBPU, apontando para a implantação de polos de desenvolvimento regional, conforme a Figura 1.

Porém, enquanto a pesquisa sobre São Paulo (1955) reservou espaço para estudar a população rural do estado, inclusive ao ponto de defender a reforma agrária, compatibilizando assim a questão agrária e a questão urbano-industrial, o estudo dos estados do Sul (1958) apontou a industrialização como condição para atingir o nível de país desenvolvido, o que ratifica, na SAGMACS, a ideia de implantação de polos de desenvolvimento regional.

\subsection{A assessoria técnica da SAGMACS para o governo do estado do Paraná}

O trabalho de 1958 para o Paraná foi realizado no âmbito da CIBPU e faz alusão ao que foi apresentado em 1955 para São Paulo. Vale destacar que o Conselho Deliberativo da CIBPU teria contratado a SAGMACS para executar um "estudo idêntico" para o Paraná, Santa Catarina e o Rio Grande do Sul. Em 1958, o Conselho da CIBPU compunha-se dos governadores dos sete estados participantes, entre eles Moysés Lupion7, do Paraná. Segundo o documento, Lebret participou ativamente nos estudos que foram desenvolvidos "dentro das diretrizes, métodos e da técnica do 'Economia e Humanismo”' (SAGMACS, 1958, p. V).

6. Contrato $\mathrm{n}^{\circ} 22$ da CIBPU, celebrado em 9 de setembro de 1955.

7. Amigo do interventor Manuel Ribas e ligado ao setor empresarial do Paraná, Moysés Lupion filiou-se ao Partido Social Democrático (PSD) em 1946 e governou o estado entre março de 1947 e janeiro de 1951, tendo sido eleito senador e novamente governador em 1955. 


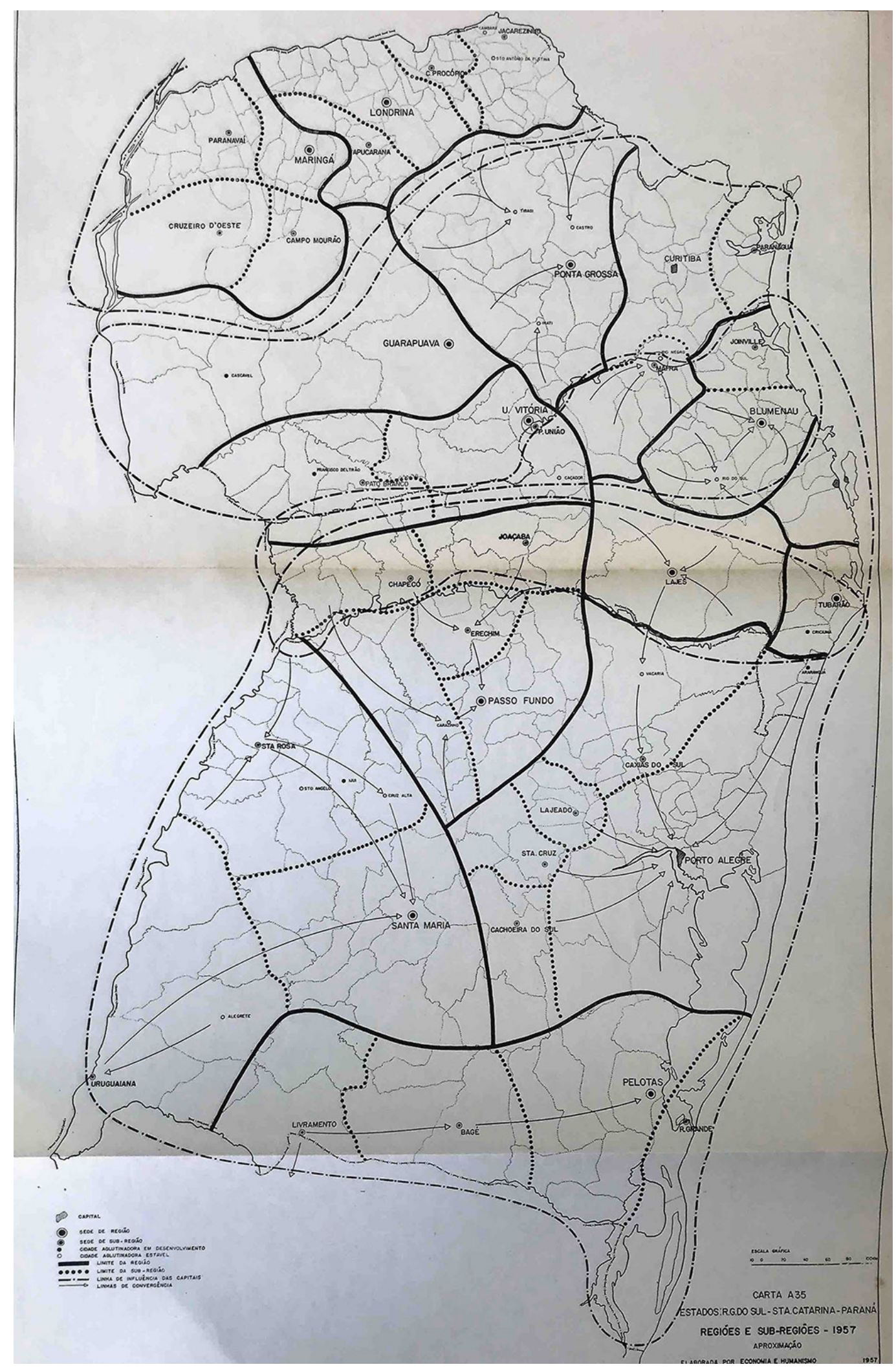

Figura 1. Regiões e sub-regiões

Fonte: SAGMACS, 1958, Carta A-35. 
Apesar da importância da inserção do Paraná na CIBPU, foi por meio da Codepar que o governo desse estado contratou a equipe da SAGMACS para formular o Plano de Desenvolvimento do Paraná (PDP), que representou a organização das metas e das ações do governo Ney Amintas de Barros Braga ${ }^{8}$ (1961-1965) na terceira fase de atuação da SAGMACS.

O governo Ney Braga pautou-se na ideia de desenvolvimentismo e no planejamento apoiado no Estado, alinhando-se à tendência verificada em âmbito nacional, pois, segundo Doustdar (2010, p. 80), esse governo era "parte de um movimento comum a vários estados voltado a reduzir as grandes disparidades regionais aprofundadas após a administração de Juscelino Kubitschek (1955-1960), bem como que as ações de seu governo se pautaram pelo desenvolvimentismo”.

O Paraná, assim como o Governo Federal e alguns estados brasileiros, vislumbrou que o desenvolvimento econômico e social, norteado pela industrialização, ocorreria como resultado das ações planejadas. No Paraná, as primeiras instituições que subsidiaram as tentativas de realizar o planejamento das ações estaduais foram o Conselho Consultivo do Planejamento Econômico do Paraná (Pladep), criado em 1955, e a Codepar, de 1962, consideradas fundamentais para atingir os objetivos estabelecidos pelos governos estaduais. Embora tenha assumido o papel de instituição de pesquisa e informação em vez de órgão planejador, o Pladep influenciou órgãos e meios acadêmicos e empresariais (IZEPÃO, 2013).

Augusto (1978) afirma que, a despeito de o "projeto de desenvolvimento paranaense” já se evidenciar principalmente nos estudos do Pladep, foi somente no início da década de 1960, na gestão de Ney Braga, que ele se explicitou. O projeto defendia a ação direta do aparelho estatal para o desenvolvimento do Paraná, por meio da industrialização, que seria alcançada "através de sua ação modernizante, racional e dinâmica” (AUGUSTO, 1978, p. 26).

Segundo essa autora (1978), a intervenção do Estado deveria ocorrer de maneira indireta e direta. Indiretamente, a ação asseguraria a infraestrutura para a instalação de indústrias e, diretamente, forneceria subsídios a elas por meio de um órgão centralizador e financiador, qual fosse: a Codepar. Magalhães Filho (2011, p. 6) considera que esse órgão foi um "instrumento emblemático de execução" do "chamado projeto de desenvolvimento paranaense", ao apoiar e fomentar iniciativas privadas e estatais que mudaram a configuração do Paraná.

8. Ney Braga iniciou sua vida política como prefeito de Curitiba em 1953. No ano de 1958, elegeu-se deputado federal e, em 1960, candidatou-se ao governo do estado pelo Partido Democrata Cristão (PDC), assumindo o cargo em 1961, no qual permaneceu até 1965. Foi nomeado para um segundo mandato entre 1979 e 1982. 
Lourenço (1999, p. 2) afirma que houve um "salto infraestrutural” com a criação da Codepar, o que "compreendeu a realização de grandes obras voltadas ao aumento da oferta de energia elétrica, à construção de rodovias e ferrovias, à adequação do porto de Paranaguá, à implantação de uma rede de armazenagem pública e à modernização das telecomunicações”. Além dos investimentos em infraestrutura por meio de recursos extraorçamentários em energia e transporte, para Gomes (2010), a Codepar deveria coordenar o processo de industrialização e realizar estudos sobre as potencialidades presentes e futuras.

Tais ações vinham ao encontro da campanha de Ney Braga para governador do Paraná, cujos pilares eram industrialização e planejamento. Governador em duas gestões, ele assumiu o Executivo estadual pela primeira vez representando a burguesia industrial-comercial, exportadora de mate e de madeira (AUGUSTO, 1978, p. 43). Além disso, conforme analisa Magalhães Filho (2011), Braga representava uma burguesia que percebia no desenvolvimento promovido pelo Estado as possibilidades para ampliar sua acumulação

Assim, o governo de Braga marcou um novo momento na história política e econômica do Paraná, e o PDP, com vigência de 1964 a 1970, foi o instrumento que representou o planejamento das ações do estado como promotor de seu desenvolvimento. Apesar de não ter sido implantado completamente, Ney Braga encaminhou políticas que se baseavam nos investimentos contidos no PDP, "os quais ainda na atualidade constituem pilares da base produtiva paranaense, sobretudo, os ligados à infraestrutura energética e de transportes e comunicações” (IZEPÃO, 2013, p. 79).

Até os anos 1960, o Paraná encontrava-se dividido entre o norte cafeeiro e o restante do estado, com frágeis relações econômicas entre os dois. O norte cafeeiro possuía fortes vínculos com São Paulo, e grande parte das safras de café continuava escoando pelo porto de Santos e não pelo de Paranaguá (IPARDES, 2006; IZEPÃO, 2013).

O PDP alinha-se ao que ocorria nacional e internacionalmente, corroborando a crença no planejamento regional e a convicção nas possibilidades do planejamento concebido e controlado pelo Estado. Sobre esse alinhamento, conforme o estudo da SAGMACS de (1958), adota-se o conceito de polos de desenvolvimento regionais, cuja matriz econômica resultava da industrialização, a exemplo do que era defendido pela Organização das Nações Unidas (ONU)' , no que tange ao desenvolvimento urbano. O PDP difere, principalmente nesse aspecto, dos apontamentos

9. A concepção de desenvolvimento da ONU consta no documento Métodos e problemas da industrialização dos países subdesenvolvidos, de 1955, que identifica a “industrialização rápida”, buscando a passagem de uma fase dedicada ao setor primário para o secundário, como ponto principal para a superação da condição de "subdesenvolvimento" (CHIQUITO, 2012a, p. 193). 
do estudo apresentado por Lebret, em 1955, para o estado de São Paulo, no qual defendeu maior integração entre o meio rural e o meio urbano e prescindiu de orientação para a industrialização, já então em desenvolvimento.

Em 1963, quando o PDP foi entregue ao governo do estado, a SAGMACS já se constituía como uma cooperativa de técnicos e concluía os planos diretores de Barretos, Sorocaba, Belo Horizonte, além de outros projetos e estudos. Cestaro (2019) observa que, nessa fase, a equipe contava com cerca de cem profissionais e não era mais coordenada por Lebret; seus membros se dividiam entre advogados, arquitetos, economistas, engenheiros, geógrafos e sociólogos. Entre fevereiro e outubro de 1963, a equipe da SAGMACS prestou assessoria para a elaboração de programas que deveriam ser revisados periodicamente, com o intuito de adequar as ações do governo à comunidade paranaense. Diante do reconhecimento da desintegração do território, a reorganização física do estado foi um dos principais temas do PDP, que deveria respeitar as necessidades e as possibilidades de desenvolvimento de cada região e fortalecer a capital, Curitiba. Além disso, foram apresentadas propostas para o desenvolvimento social e econômico e o estudo para a reorganização do Serviço Público do Estado (CORDOVIL, 2017).

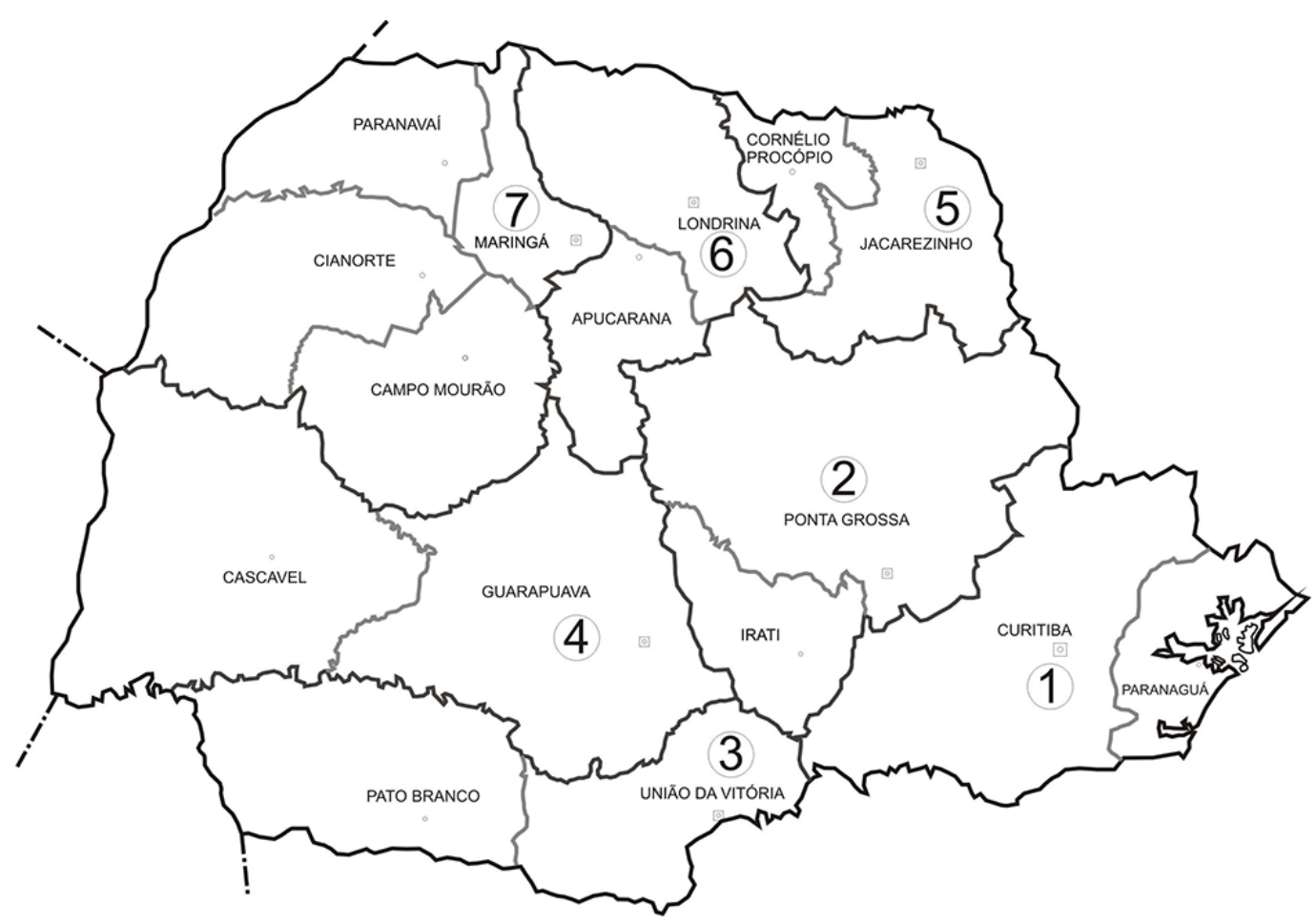

Figura 2. Regiões e sub-regiões de planejamento e polos e subpolos regionais Fonte: Paraná, 1963, prancha 13. Redesenhada pelos autores. 
No que tange à organização físico-territorial, o PDP divide o estado hierarquicamente em sete regiões e dezesseis sub-regiões (ver Figura 2). Segundo o PDP, as regiões possuem características específicas, mas podem ser agrupadas em razão de haver critérios comuns, como a existência de polarização territorial da sede, a possibilidade de autossuficiência, a população entre 500 mil e 1,5 milhão de habitantes (excetuando-se a capital, Curitiba, cuja população era maior) e uma área de abrangência de, no máximo, 30 mil km², além da correspondência do escalão regional à estrutura administrativa, o que facilitaria a organização horizontal e vertical da Administração Pública (PARANÁ, 1963).

O PDP pretendia ser um “instrumento de modificação das estruturas” com o propósito de promover o "desenvolvimento integral e harmônico", tendo como diretriz a expressão consagrada pelo economista François Perroux, um dos fundadores do EH: "todo homem e todos os homens" (PARANÁ, 1963).

Com essa expressão, Perroux (1967, p. 383-384) defendia a manutenção da individualidade do homem e de seus valores. A economia, para esse autor, deveria preocupar-se com o homem - e não somente com o aumento da produção e da riqueza, o que beneficiaria poucas pessoas. Ao conceituar o que entende pelo termo “custos do homem”, ele expõe que a preservação moral, a saúde física e mental, a liberdade e a educação, além do tempo livre, constituiriam os pontos essenciais capazes de garantir o mínimo de subsistência para as condições fundamentais da vida e que, portanto, isso deveria ser assegurado para o ser humano em contraponto à economia da avareza.

O PDP organiza o território por meio dos escalões territoriais hierarquizados com base em funções e área de influência, e o desenvolvimento social e econômico ocorreria valendo-se da integração desses escalões e da estrutura administrativa estadual. Em sua metodologia, a análise técnica e científica do PDP também parte dos escalões territoriais hierarquizados, na tentativa de conciliar economia e desenvolvimento humano e social, com a distinção de áreas isoladas do ponto de vista das funções econômicas e sociais, tributárias de sistemas extraestaduais, o que explicava o enfraquecimento da unidade política e administrativa (CORDOVIL, 2017).

O primeiro dos escalões é a região. Além das sete regiões e das dezesseis sub-regiões, há em torno de cinquenta zonas supralocais e inumeráveis comunidades locais urbanas e rurais no Paraná, evidenciando os escalões sucessivos do território responsáveis pelas tarefas de desenvolvimento. A ação do estado, por intermédio de oito programas ${ }^{10}$ sistematizados de acordo com os recursos a se-

10. Os programas são: 1. Eliminação das condições sub-humanas de vida; 2. Atendimento das necessidades básicas da população; 3. Atendimento das necessidades de superação da população; 4. Participação 
rem despendidos, se iniciaria pelos escalões mais amplos e menos numerosos, ou seja, nas regiões e nas sub-regiões. Portanto, são nos escalões superiores que se definem as metas e os recursos globais do PDP, cujos efeitos se evidenciam nas comunidades menores.

O modelo adotado pelo Movimento Economia e Humanismo pressupõe que "as comunidades têm necessidades escalonadas segundo o grau de imperatividade relativamente à elevação dos níveis de vida, isto é, face ao processo de desenvolvimento integral e harmonizado" (PARANÁ, 1963, p. 4). Esse apontamento mostra o alinhamento da SAGMACS com a inserção dos polos de desenvolvimento regional, mas preserva a ideia original do Economia e Humanismo, que visava entender a ordem humana e reconhecer as possibilidades advindas das condições socioculturais encontradas, trabalhando na própria comunidade a fim de entender a sua realidade para, então, desenvolver a economia.

Nos limites deste texto, destacam-se aproximações entre Lebret e o urbanista francês Gaston Bardet, que, considerando o cenário da França e sua concentração urbana, enfatiza a necessidade da abordagem sobre escalões de análise hierarquizados para o estudo de um plano nacional, incluindo a noção de região e das escalas mais próximas dos habitantes da cidade. Cestaro (2019) relaciona a influência de Frédéric Le Play na proposta de Bardet no que se refere à formação de um método de investigação que se vale de amostragem populacional. Pontual (2016a, p. 94-95) evidencia a abordagem de Bardet sobre a teoria das escalas comunitárias na publicação da Revue Économie et Humanisme, do ano de 1943, e na obra Mission de l'urbanisme, escrita em 1946-1947 e tema de sua primeira conferência no Brasil. Tanto Frey (1999) como Pontual (2016a) afirmam que Bardet parte da escala elementar ou patriarcal, passa pela doméstica, paroquial ou de bairro, da cidade propriamente dita, até chegar aos últimos dois escalões: a metrópole regional e a metropolitana capital. A análise da atração da população está representada na Figura 3, correspondendo à peça gráfica 9, no PDP, que evidencia os polos hierárquicos e suas áreas de influência, definidos como polo interestadual, polo regional desenvolvido, polo regional desenvolvido II, polo regional em formação, polo sub-regional em formação e polo supralocal. Observa-se na Figura 3 que a hierarquia se define do escalão territorial maior para o menor, e Curitiba consiste na polarização interestadual, com as demais cidades decrescendo em escala conforme evidenciado na denominação: Londrina é uma das polarizações regionais

da população no processo de desenvolvimento; 5. Aumento da diversificação agrícola; 6. Estabilidade e dinamismo da economia; 7. Proteção à produção de especialização do Paraná; 8. Programação especial para implantação territorial. 
desenvolvidas; Ponta Grossa é polarização regional desenvolvida II; Cascavel, polarização regional em formação; Irati, polarização sub-regional em formação, e Loanda, polarização supralocal.

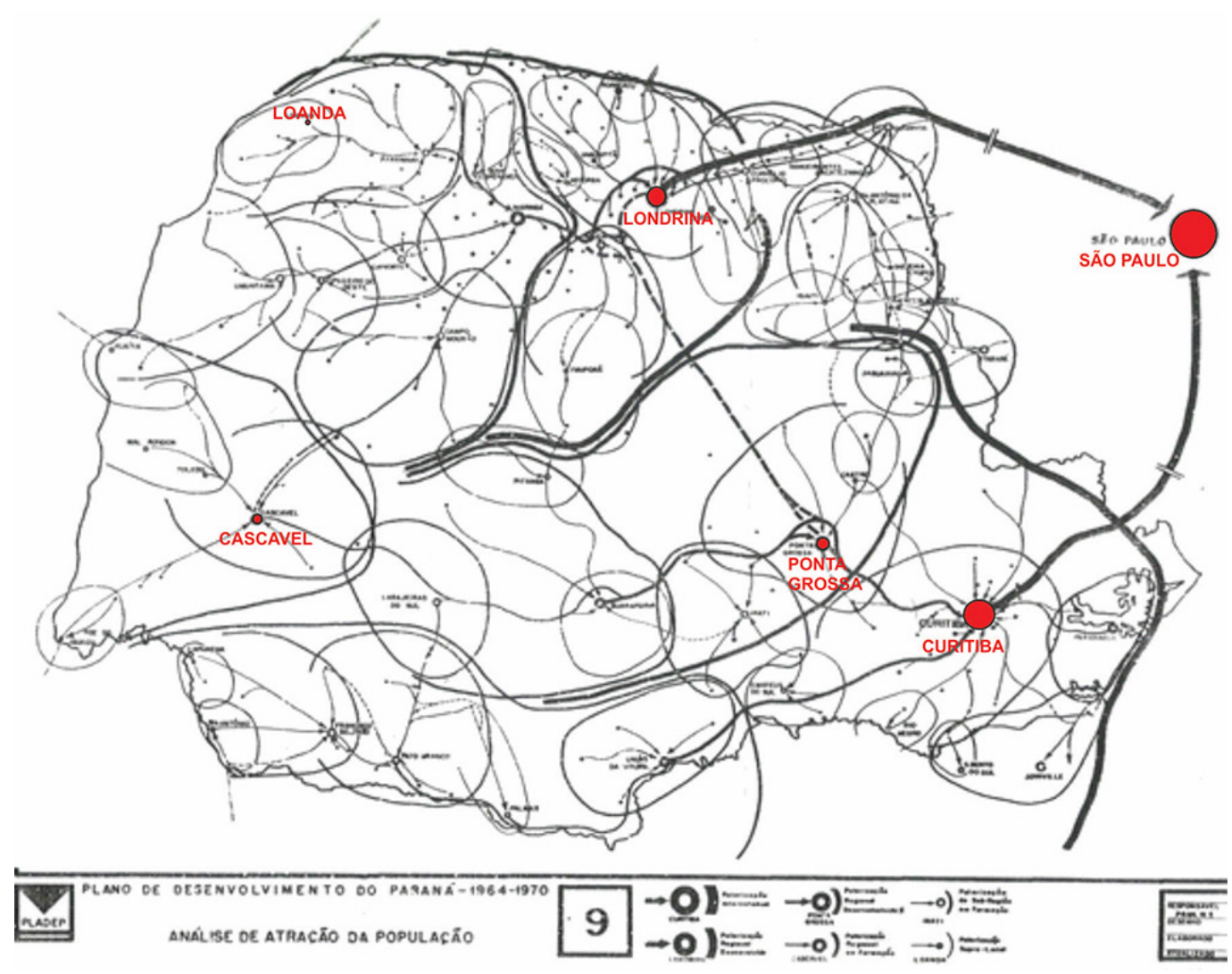

Figura 3. Análise de atração da população - hierarquia dos escalões territoriais Fonte: Paraná, 1963, prancha 9. Modificada pelos autores.

Na concepção da equipe da SAGMACS, o território socialmente ocupado apresenta inúmeras funções que são exercidas por unidades funcionais cuja atuação ocorre em áreas de influência e por meio de fluxos de relações.

A participação da população é outra dimensão recorrente no PDP e deveria acontecer como resultado da ação de grupos comunitários. O associativismo é considerado fundamental para a eficácia do Plano. A "democratização do planejamento” ocorreria por meio das consultas periódicas à população, que participaria da formulação e da revisão dos objetivos, em uma atuação corresponsável pelo planejamento, de modo a atingir uma "dimensão essencial do homem que é a superação, meio e fim” (PARANÁ, 1963, p. 21). Na metodologia de pesquisa, o reconhecimento da realidade paranaense deu-se por meio de consulta de documentos exis- 
tentes e da pesquisa de campo em 550 entrevistas, que pretendeu representar os diferentes níveis da população, bem como das atividades e funções dos setores público e privado.

Além da aproximação com a premissa do desenvolvimento harmônico de Perroux (1967), que tinha como proposta entender a ordem humana, trabalhando na própria comunidade para entender sua realidade, a metodologia empregada pela SAGMACS demonstra a concepção de que o crescimento se manifesta diferentemente em pontos ou polos do território, com intensidades distintas, criando efeitos que variam no conjunto da economia.

Nesses aspectos, o planejamento aproxima-se do núcleo comunitário, almejando que a população tivesse papel importante nas decisões políticas, partindo das regiões de planejamento, vistas como polos de atividades estratégicas para o alcance do progresso econômico e do desenvolvimento social, com tarefas relacionadas às funções internas e externas, e atendendo ao duplo objetivo da estrutura territorial, a descentralização e a integração do Estado.

\section{Considerações finais}

Analisamos a atuação da SAGMACS no planejamento urbano e regional do Brasil em uma década, a partir de 1952 até o início dos anos 1960, em dois trabalhos que envolveram o planejamento do estado do Paraná e foram contratados por órgãos estaduais brasileiros. Tais trabalhos representam, respectivamente, o início das atividades voltadas ao campo do planejamento urbano e regional pela SAGMACS no Brasil e seu encerramento, marcado pela emergência do golpe militar em 1964.

Foi dado destaque ao contexto nacional e internacional do pós-guerra, que levou Lebret e os adeptos do Economia e Humanismo, fundado em 1941, a se aproximarem do aparelho estatal francês, a partir de 1944, com o Movimento Republicano Popular e seu programa "democrata-cristão". O argumento se relacionava com a pretensão de construir uma terceira via econômica, nem capitalista nem socialista - dualidade que, naquele momento, polarizava o mundo. Criaram-se, a partir de 1945, laboratórios locais vinculados ao Economia e Humanismo, os quais chegaram ao Brasil em 1947, quando Lebret fundou a SAGMACS.

No Brasil do pós-guerra, transformações significativas ocorriam na matriz econômica, num contexto de modernização do parque industrial e de afluxo populacional para as cidades que se estendiam sistematicamente no território. Nesse período, destaca-se, também, a redemocratização, com o retorno no país das eleições diretas para presidência, em 1945. Ao mesmo tempo, os governos investiam 
na reforma e na modernização do estado, trazendo para si as atividades de planejamento, com vistas a enfrentar os problemas de desigualdades regionais e de dependência econômica.

Assim, conforme demonstrado, foi com a eleição de Lucas Nogueira Garcez para o governo do estado de São Paulo que Lebret retornou ao Brasil e a SAGMACS se inseriu no campo do planejamento territorial, tendo na CIBPU o marco inicial para essas práticas. Foi a partir desse trabalho que o desenvolvimento urbano e regional passou a figurar na SAGMACS, com a realização de trabalhos e estudos voltados ao desenvolvimento das cidades, rendendo a aproximação de Lebret com os profissionais do urbanismo, como o engenheiro pernambucano Antônio de Bezerra Baltar, e com a Escola Politécnica e a Faculdade de Arquitetura e Urbanismo da USP.

O Plano de Desenvolvimento do Paraná representou o alinhamento do governo Ney Braga à tendência que se verificava nacionalmente, que apostava no desenvolvimento e no planejamento efetuado pelo estado para reduzir as desigualdades regionais, num território estadual marcadamente desarticulado entre o norte e o sul e a capital, Curitiba. Foram investigadas as filiações teóricas e metodológicas do PDP que sistematizaram o estado em foco em comunidades territoriais hierarquizadas, às quais se vincularam os programas de planejamento e as estratégias de atuação das políticas públicas estaduais. A divisão territorial proposta com base nas comunidades territoriais apresenta filiações nos estudos de Le Play e de Bardet, demonstrando em sua concepção as ressonâncias das teorias do pensamento francês no PDP, bem como alguns princípios de Perroux e do Movimento Economia e Humanismo. As premissas do PDP certamente constituíram as bases do desenvolvimento e da modernização do estado, o que fez com que o primeiro governo de Ney Braga fosse considerado o ponto de inflexão na política paranaense.

No que se refere às repercussões do Plano de Desenvolvimento do Paraná, evidenciou-se principalmente a diretriz para o planejamento territorial dos polos das regiões, que teve como resultado a elaboração de planos diretores para tais municípios polos e a instituição de setores ou órgãos de planejamento na estrutura técnico-administrativa das prefeituras, temas que abrem campo tanto para exploração em novas pesquisas como para futuro aprofundamento.

Assim como no Brasil, Lebret difundiu o pensamento do Economia e Humanismo, a partir de 1947, em outros países da América Latina, como Chile, Argentina, Colômbia e Uruguai. A exemplo do estudo sobre a SAGMACS, a investigação sobre sua atuação e sobre as instituições de urbanismo criadas na época constitui-se em contribuição relevante para a historiografia, no intuito de relacionar os pensamentos e as ações no território, vinculados aos contextos históricos dos demais países 
nos quais Lebret e o Economia Humanismo atuaram. A contribuição reside na análise da história das ideais e de suas ressonâncias no planejamento urbano e regional no Brasil e em outros pontos da América Latina.

O estudo pretendeu evidenciar os planos para o Paraná no campo das análises historiográficas do planejamento urbano e regional no Brasil como mais um elemento da atuação da SAGMACS, o que propicia a ampliação das reflexões sobre suas referências teóricas e aplicações práticas e o estabelecimento de possibilidades para novas análises sobre as redes profissionais e políticas em contextos distintos. Adicionalmente, situa-se a SAGMACS no campo da história do urbanismo do período, até a interrupção de seus trabalhos em decorrência do golpe militar de 1964.

\section{Referências}

ANGELO, M. R. de. Louis-Joseph Lebret e a SAGMACS. A formação de um grupo de ação para o planejamento urbano no Brasil. São Paulo: Alameda, 2013.

AUGUSTO, M. H. O intervencionismo estatal e ideologia desenvolvimentista. São Paulo: Símbolo, 1978.

BOSI, A. Economia e Humanismo. Revista de Estudos Avançados, São Paulo, v. 26, n. 75, 2012.

CESTARO, L. R. Planejamento urbano e regional no Brasil: as ideias, planos e contribuições de Lebret e da SAGMACS. São Paulo: Annablume, 2019.

CHIQUITO, E. de A. A Comissão Interestadual da Bacia Paraná-Uruguai: do planejamento de vale aos polos de desenvolvimento. 2012. Tese (Doutorado) - Programa de Pós-graduação do Instituto de Arquitetura e Urbanismo da Universidade de São Paulo, São Paulo, 2012a.

. A criação da Comissão Interestadual da Bacia Paraná-Uruguai: referencial norte-americano no planejamento regional brasileiro dos anos 1940-50. Revista FAAC Unesp, v. 2, n. 1, p. 69-78, 2012b.

CORDOVIL, F. C. S. As filiações teóricas dos escalões territoriais de análise do Plano de Desenvolvimento do Paraná elaborado pela SAGMACS. In: III SEMINÁRIO URBANISMO E URBANISTAS NO BRASIL, 2017, Recife. Anais [...]. Recife: MDU-UFPE, 2017. p. 62-76. Tema: Urbanistas e urbanismo moderno: trajetórias múltiplas e juízos historiográficos.

DOUSTDAR, N. M. O paranismo atualizado: a Democracia cristã e o planejamento no primeiro governo Ney Braga. 2010. Tese (Doutorado) - Programa de Pós-graduação em Sociologia da Universidade Federal do Paraná, Curitiba, 2010.

ÉCONOMIE ET HUMANISME. Statuts d'Économie et Humanisme. Deposés a la Prefecture du Bouche-du- Rhône. 1941.

. Manifeste d’Économie et Humanisme. Revue Économie et Humanisme, n. 1, 1942. 
FELDMAN, S. 1950: a década de crença no planejamento regional no Brasil. In: XIII ENCONTRO NACIONAL DE PÓS-GRADUAÇÃO E PESQUISA EM PLANEJAMENTO URBANO E REGIONAL, 2009, Florianópolis. Anais [...]. Florianópolis: ANPUR, 2009. p. 1-23. Tema: Planejamento e gestão de território: escalas, conflitos e incertezas.

FREY, J. P. Gaston Bardet. L'espace social d'une pensée urbanistique. Les Études sociales. Voyages d'expertise, n. 130, p. 57-82, $2^{\circ}$ sem. 1999.

GARDIN, C. A Comissão Interestadual da Bacia Paraná-Uruguai no planejamento regional brasileiro (1951-1972). Dourados, MS: Ed. da UFGD, 2009.

GOMES, C. A. F. Planejamento e industrialização em regiões periféricas: as ideias da Cepal no Projeto Paranaense de Desenvolvimento. 2010. Tese (Doutorado) - Instituto de Ciências Humanas e Filosofia da Universidade Federal Fluminense, Rio de Janeiro, 2010.

IPARDES - INSTITUTO PARANAENSE DE DESENVOLVIMENTO. O Paraná reinventado: política e governo. 2. ed. Curitiba: Ipardes, 2006.

IZEPÃO, R. L. O planejamento governamental no Paraná. Economia, estado e política econômica. Maringá: , Eduem, 2013.

LEBRET, L. J. Rapport Conclusions provisoires du Voyage d'étude. [S.I.], 1952.

LEME, M. C. da S.; LAMPARELLI, C. M. A politização do urbanismo no Brasil: a vertente católica. In: IX ENCONTRO NACIONAL DE PÓS-GRADUAÇÃO E PESQUISA EM PLANEJAMENTO URBANO E REGIONAL, 2001, Rio de Janeiro. Anais [...]. Rio de Janeiro: ANPUR, 2001. p. 675-687.

LOURENÇO, G. M. Economia paranaense: restrições conjunturais e avanços estruturais. Revista da FAE, 2, n. 3, p. 1-8, set.-dez. 1999.

MAGALHÃES FILHO, F. de B. Da construção ao desmanche: análise do Projeto de Desenvolvimento Paranaense. Curitiba, Ed. da UFPR, 2011.

PARANÁ (Governo do Estado). Plano de Desenvolvimento do Paraná. Documento preliminar elaborado pela SAGMACS. Curitiba: Codepar: Pladep, 1963.

PELLETIER, D. Économie et Humanisme: De l'utopie communautaire au combat pour le tiers monde (1941-1966). Paris: Les Éditioins du Cerf, 1996.

PERROUX, F. A economia do século XX. Lisboa: Herder, 1967.

PONTUAL, V. P. Lebret na América Latina. In: XXVIII CONGRESSO INTERNACIONAL DA ASSOCIAÇÃO LATINO-AMERICANA DE SOCIOLOGIA, 2011, Recife. Anais [...]. Recife, 2011.

. O urbanismo aplicado do mestre Gaston Bardet: conferências, cursos e instituições. Revista Urbana, 8, n. 3, p. 89-110, 2016a.

. Louis-Joseph Lebret e a América Latina: um exitoso laboratório de experiências em planejamento humanista. São Paulo: Letra Capital: UFPE, 2016b.

ROLDAN, D. D. Um ideário urbano em desenvolvimento. A experiência de Louis-Joseph Lebret em São Paulo de 1947 a 1958. 2012. Dissertação (Mestrado) - Programa de Pós-graduação da Faculdade de Arquitetura e Urbanismo da Universidade de São Paulo, São Paulo, 2012. 
SAGMACS. Problemas de desenvolvimento. Necessidades e possibilidades do estado de São Paulo. São Paulo: CIBPU: SAGMACS, 1955.

Problemas de desenvolvimento. Necessidades e possibilidades dos estados do Rio Grande do Sul, Santa Catarina e Paraná. São Paulo: CIBPU: SAGMACS, 1958.

SAUVY, T. Monde, une planète. L'Observateur: politique, economique et littéraire, n. 118, p. 14, 1952. 


\section{Lucas Ricardo Cestaro}

Graduado em Arquitetura e Urbanismo pela Universidade Metodista de Piracicaba (2003), desenvolveu o mestrado (2006-2009) e o doutorado (2011-2015) pelo Instituto de Arquitetura e Urbanismo da Universidade de São Paulo (IAU-USP), campus de São Carlos, com apoio da Fapesp. Atua como professor do Departamento de Arquitetura e Urbanismo na Universidade Federal do Paraná (UFPR), onde é pesquisador vinculado ao Laboratório de Habitação e Urbanismo (LAHURB).

Email: lucas_cestaro@uol.com.br

ORCID: 0000-0002-1267-5019

Contribuição de autoria: conceituação; curadoria de dados; análise formal; investigação/pesquisa; metodologia; escrita primeira redação; escrita, revisão e edição.

\section{Fabíola Castelo de Souza Cordovil}

Graduada em Arquitetura e Urbanismo pela Universidade Federal de Santa Catarina e mestre em Geografia pela mesma instituição. Pós-doutora em Geografia também pela UFSC e doutora em Arquitetura e Urbanismo pela Universidade de São Paulo (USP). Professora associada ao Departamento de Arquitetura e Urbanismo da Universidade Estadual de Maringá (UEM). Docente permanente do Programa de Pós-graduação em Geografia e do Programa de Pós-graduação em Políticas Públicas, ambos da UEM. Pesquisadora do Observatório das Metrópoles, núcleo Maringá.

Email: fabiolacordovil@gmail.com

ORCID: 0000-0002-1065-3908

Contribuição de autoria: conceituação; curadoria de dados; análise formal; investigação/pesquisa; metodologia; escrita primeira redação; escrita, revisão e edição.

Submissão: 20 de janeiro de 2020.

Aprovação: 4 de novembro de 2020.

Como citar: CESTARO, L. R.; CORDOVIL, F. C. S. O planejamento territorial no Paraná baseado na atuação do Movimento Economia e Humanismo no Brasil. Revista brasileira de estudos urbanos e regionais. v. 22, E202043, 2020. DOI 10.22296/2317-1529.rbeur.202043.

Artigo licenciado sob Licença Creative Commons CC BY 4.0.

https://creativecommons.org/licenses/by/4.o/deed.pt_BR 